\title{
Camels in Asia and North Africa: Interdisciplinary Perspectives on Their Past and Present Significance
}

\author{
Eva-Maria Knoll and Pamela Burger, eds. 2012. Verlag der Österreichischen Akademie der Wissenschaften \\ (Austrian Academy of Sciences Press), Wien (Vienna). Pp. 298, 111 colour illustrations, 33 black-and-white \\ illustrations. €45.00 (paperback). ISBN 978-3-7001-7244-4.
}

\section{Reviewed by Robin Bendrey}

Reviewer address: Department of Archaeology, University of Reading, Whiteknights Box 226, Reading, RG6 6AB, UK. r.bendrey@reading.ac.uk

Received: October 2, 2014

Volume: 5:129-131

Published: November 13, 2014

(C) 2014 Society of Ethnobiology

This volume is concerned with the Old World camels: the extant population of wild two-humped camels (Camelus ferus Przewalski Camelidae), the domestic two-humped Bactrian camel (Camelus bactrianus Linnaeus Camelidae), and the domestic one-humped dromedary (Camelus dromedaries Linneaus Camelidae). It stems from an international conference organised by the two editors of the volume in 2010 at the Austrian Academy of Sciences. Conceived as a truly interdisciplinary meeting, this publication brings this approach to fruition in a rich and diverse account of the past, present, and indeed future, of camel-human relationships. The volume is composed of 26 chapters which, excluding the introduction by Knoll and afterword by Bulliet, are divided across four main sections.

The first section of the book consists of three chapters dealing with the relationships between the Old World camels, and in particular the origins and relationships of the domestic forms. This has long been an enigmatic question, in part due to the sketchy archaeological record. In the past, some scholars have argued that the two Old World domestic camels were both descended from only one wild form, the two humped camel, based on the absence of a modern wild one-humped camel, the fact that Bactrian camels and dromedaries produce fertile offspring when crossed, and observations in the late 19th century C.E. by L. Lombardini that dromedaries passed through a two-humped stage in their embryonic development. This notion is now, however, convincingly refuted. The chapter by Knospe et al. presents a study of foetal hump development that disproves the idea that dromedaries pass through a two-humped stage in their development. Also, genetic studies show that the two camels have separate ancestors and that their separation is of significantly greater antiquity than the Holocene timescale of human domestications (chapter by Burger; Ji et al. 2009). Burger reviews the genetic evidence for the origins of the domestic camels, and highlights the advances being made in our understanding of these processes. This chapter covers a lot of ground, but the treatment occasionally feels a little too concise, for example Burger hints at the modern mitochondrial DNA evidence for dromedaries pointing to 'two domestication scenarios', but does not elaborate on what these are. The hybridization of the one-humped and twohumped camels by humans is the subject of Faye and Konuspayeva's chapter. In a fascinating short study, they detail the social and economic significance of camel hybridization in modern Kazakhstan.

Four chapters discuss aspects of the current populations of wild two-humped camels (C.ferus) in Central Asia. These are critically endangered, surviving only in small numbers in four discrete areas. The human impact on, and conservation challenges of, these animals are discussed by Yadamsuren et al., Lei et al., Walzer et al., and Silbermayr and Burger. Hybridization with the very large surrounding domestic population is one very serious threat to the wild camels, which has been recorded as deliberately initiated on occasion to improve the fitness of domestic stock (Silbermayr and Burger).

The Bactrian camel (C. bactrianus) is the subject of three chapters. Returning to the difficult question of domestication, Trinks et al. report analyses of mitochondrial DNA of both archaeological and modern camels and argue that low genetic diversity in 
the modern domestic populations supports the idea of a single camel domestication centre. Although the geographic origins of the domestic Bactrian camel are still unclear, what is certain now from the DNA evidence is that they did not descend from the extant wild C. ferus population, but from a separate twohumped ancestor (see also Ji et al. 2009). Moving from their population biology, to their social significance, two chapters - by Lang and by Chuluunbaatar - discuss the place of the camel in Mongolian culture.

By far the largest section of the book is committed to domestic dromedaries, starting with an up-todate summary of the zooarchaeological evidence for their domestication by H-P and M Uerpmann. This is an excellent critical account of the subject, reflecting the substantial and long-term contribution of these authors to the archaeology of the Arabian Peninsula. The result is a robust understanding of when domestic dromedaries appear in southeast Arabia, although we still do not have a good handle on precisely where, when and why dromedaries were first domesticated. Other chapters further develop the history of dromedary use as transport animals in Arabia. Dostal's thought provoking reflection links dromedary anatomy, riding technology and the regional significance of the Bedouin in warfare and long distance trade. Heiss considers South Arabian camel caravans and in particular the $10^{\text {th }}$ century CE accounts of al-Hasan al-Hamdānī who describes the equitable communal organization of caravans, which could consist of thousands of camels stretching over several miles. Providing nuanced interpretations of ethnographic observations from the Tihama, in southwest Arabia, Gingrich identifies the essential roles of dromedaries in transport, powering wells and mills, and, importantly, symbolism.

The significance of dromedaries to diverse modern human economies is reflected in a range of further contributions to this section: dromedary husbandry and use in Syria (by Tabbaa) and Pakistan (by Iqbal); camel milk production and use, in chapters by Dioli and also Younan and Mwangi, and milk shelf life (by Zubeir); and Bakhsh et al. consider the position of both camel milk and urine in Arabian Folk Medicine. Ethnography also makes a significant contribution to the book, with Fischer's study of the Imuhar nomads (also known as the Tuareg) of South Algeria, and Varisco's chapter on the ethnobotany of camel diet. Abdussamad et al. present a photo-essay on camel phenotypes, reproduction and foetal wastage, and herd health in the Nigeria-Niger corridor: these are significant issues for boosting camelrearing here and improving food security. Diverse other aspects are also considered, for example, tourist camel trekking in Jordan's desert area (chapter by Shunnaq and Shunnaq).

As an interdisciplinary overview of the state of current knowledge and method in the study of the past and present Old World camels, this book is highly recommended. It will be of interest to scholars across diverse disciplines, including archaeologists, historians, biologists, cultural anthropologists and conservationists. Although some studies have been published before, it does represent a unique resource collected together in one place. The volume is generally edited to a very high standard, and has rich and copious colour illustrations, which although divorced from the text as a separate section at the back of the book add significantly to the volume in the diversity and quality of illustrations.

As Bulliet points out in his afterword to the volume, unlike the other Old World major domestic ungulates that have spread around the globe, camel husbandry and use is largely restricted to its native habitats and those areas that share similar climatic extremes. Bulliet argues that the economic utility of camels derives from their outstanding strength, tractability and stamina and their adaptation to extremely arid environments; but that the greater costs, in terms of human investment, of raising the slow-maturing dromedary in non-desert habitats, compared to other faster maturing domestic animals (see Wilson 184, 135-136), makes them economically uncompetitive in these environments. This pragmatic blend of economic and ecological perspectives in explaining the modern distribution and use of camels links in with increasing understanding of the biogeography of human-animal relationships in the Holocene (e.g. Bendrey 2014; Manning et al. 2012). Understanding these processes in the longue durée has significant modern relevance for diverse communities contending with ensuring food security from pastoral farming in the face of changing regional climates (e.g. Kayunyu and Wanjohi 2014).

This book represents an excellent starting point for the next wave of camel research. The volume highlights the vital role of Old World camels in the human past and present - in particular in regional food production and transport contributions to warfare and long-distance trade and communication - 
and also potential contributions for the future. Although the role of camels as transport animals is reduced in the modern world due to the rise of motorized transport, they clearly remain a powerful cultural icon. It is particularly in their adaptation to arid environments that their husbandry still holds great significance for human food production in marginal environments.

\section{References Cited}

Bendrey, R. 2014. Population genetics, biogeography, and domestic horse origins and diffusions. Journal of Biogeography 41: 1441-1442.

Ji, R., P. Cui, F. Ding, J. Geng, H. Gao, H. Zhang, J. Yu, S. Hu, and H. Meng. 2009. Monophyletic origin of domestic bactrian camel (Camelus bactrianus) and its evolutionary relationship with the extant wild camel (Camelus bactrianus ferus). Animal Genetics 40: 377-382.

Kagunyu, A.W. and J. Wanjohi. 2014. Camel rearing replacing cattle production among the Borana community in Isiolo County of Northern Kenya, as climate variability bites. Pastoralism, 4(1): 1-5.

Manning, K., S. Downey, S. Colledge, J. Conolly, K. Stopp and S. Shennan. 2013. The origins and spread of stock-keeping: the role of cultural and environmental influences on early Neolithic animal exploitation in Europe. Antiquity 87: 1046-1059

Wilson, R. T. 1984, The camel. Longman, London and New York. 